\title{
ASSESSMENT OF THE KNOWLEDGE, ATTITUDE, AND PRACTICE OF ANTIBIOTIC PRESCRIPTION AMONG A GROUP OF DENTISTS IN EGYPT: A CROSS-SECTIONAL SURVEY
}

\author{
Ola Abd El-Geleel ${ }^{*}$, Basma Gamal ${ }^{*}$ and Nour Wahba ${ }^{* *}$
}

\begin{abstract}
Objectives: The purpose of this survey is to investigate the knowledge, attitudes and practices related to antibiotic prescription patterns in a group of dentists in Egypt.

Materials and Methods: A cross-sectional survey was conducted electronically using online google forms. It included inquiries in the form of close-ended questions to be answered in tickbox format, the questions mainly uncovered, the participants' "Knowledge" about the problem of antibiotic resistance and its association with professional mal-practices, and also their "Attitudes and practices" concerning antibiotic prescriptions in different clinical conditions. 500 participants answered the questionnaire over a period of three months.

Results: Most of the participants prescribed Amoxicillin or Amoxicillin + clavulanic acid in conditions that warrant antibiotics usage. A close proportion preferred a treatment duration of 5-7 days. Although, $96 \%$ of the responses came in favor of antibiotic prescription in serious clinical conditions as facial cellulitis, still varying proportions of the sample chose to prescribe antibiotics for conditions that do not necessitate their usage as "localized intra-oral abscesses", "sinus tracts and fistulas", "luxation injuries" and "managing viral infections".

Conclusions: Although the participants showed considerably adequate knowledge of the bacterial resistance problem, their practices showed varying degrees of deviation from the guidelines of antibiotic prescriptions set by the AAPD.
\end{abstract}

KEYWORDS: Antimicrobial resistance, Antibiotic prescription, prescription, Mis-use .dentists

\section{INTRODUCTION}

Antibiotics are considered one of the greatest inventions of the 20th century since, infectious diseases contributed to high mortality and morbidity rates throughout the world ${ }^{[1]}$.
The use of antibiotics is an integral part of dentistry and prescribing antibiotics is a privilege that must be practiced judiciously ${ }^{[2]}$. The abuse of antibiotics by dentists however is reported worldwide ${ }^{[3-5]}$.

\footnotetext{
* Lecturer, Pediatric Dentistry and Dental Public Health Department, Ain-Shams University, Cairo, Egypt.

**Assistant Lecturer, Pediatric Dentistry and Dental Public Health Department, Ain-Shams University, Cairo, Egypt.
} 
It has been acknowledged that there are six possible results of antibiotic use, and only one of them is a positive outcome for the patient which occurs when the antibiotic helps a host's immune system to gain control and eliminate the infection. The negative results however include; toxicity or allergy, superinfection with resistant bacteria, chromosomal mutations to resistance, gene transfer to vulnerable organisms and expression of dormant resistant genes $^{[6]}$. Moreover, the unwarranted antibiotics usage also leads to an increased burden on the patient and the society by increasing treatment costs ${ }^{[2]}$.

Antibiotic abuse has already been considered as a pandemic community issue by World Health Organization (WHO) ${ }^{[7]}$ and as a result; antibiotic resistance has been determined to be one of the world's most pressing public health problems [8], since the appearance of multidrug-resistant bacterial strains, which are highly resistant to many antibiotic classes ${ }^{[9]}$. This resistance may result in longer-lasting illnesses, more doctor visits, extended hospital stays, the need for more expensive medications, and even death ${ }^{[8]}$.

The misuse of antibiotics could be due to insufficient knowledge of prescribers, the demand of the patients, weak spreading awareness among patients through health care providers and negative attitude and practice pattern ${ }^{[10-12]}$.

In addition, antibiotics are considered the most sold drugs in the developing countries. As there are not always restrictions to bring valid prescriptions for buying medications except for narcotics and few tranquilizers, and in most cases, medicines including antibiotics can be bought even without a prescription $^{[13]}$.

It has been argued that the containment of antibiotic resistance can only take place after significant reduction in their prescription and usage ${ }^{[14,15]}$. Therefore, the decision to prescribe an antibiotic is critical, and the potential positive results must be carefully weighed against the potential negative consequences ${ }^{[16]}$.

To the date of the present study, literature is scarce regarding antibiotic prescription practices aimed at treating dental infections of children in Egypt. For this reason, this survey was conducted so that a better and concise understanding of such behaviours could be achieved.

\section{METHODS}

\section{Study design and sampling}

This study is a cross-sectional survey conducted to determine the knowledge, attitude and practice of antibiotic prescriptions for children among a group of dentists who received their dental education in Egyptian universities.

The tool used in the current study was in the form of a self-administered questionnaire survey that was generated and conducted using online Google Forms, the questions of which were formulated following in-depth review of questionnaires utilized in previous surveys with similar objectives [17-20].

After being approved by the ethical committee of Ain Shams University, the survey questionnaire was pilot tested on a small group of dentists to check the feasibility and applicability then necessary corrections were made, and the questionnaire was finalized.

The sample included a) Dental Interns in private and public dental schools; b) General Practitioners (GP's); c) Postgraduate dental students (in any of the dental fields); d) All dental specialties (Clinical as well as Academic) and e) Staff members of private and public dental schools. And in order to ensure that the participants' knowledge and skills obtained during the course of their dental education in the Egyptian universities, dental students and dentist who attended dental school in foreign countries other than Egypt were excluded from the sample. 
The sampling methodology adopted was the convenience sampling, where a total of one thousand e-mails were sent to potential participants. Only 500 participants have answered the questionnaire in the online form over a period of three months. The authors, however, did not participate in the survey to avoid any possible bias.

In addition to inquiries about personal and demographic data, the questionnaire also included '13" close-ended questions in tick-box format, to explore "Knowledge" about antibiotics usage and the antibiotic resistance problem, and also the "Attitudes and practices" of participants regarding their antibiotic prescriptions.

\section{Data collection and statistical analysis}

The survey questionnaire link was sent by an e-mail to one thousand dentists, only $(\mathrm{N}=500)$ dentists filled in the online questionnaire form. The authors did not participate in the survey to avoid any possible bias. Data was then statistically analysed using SPSS program.

\section{RESULTS}

\section{Demographics Assessment}

The mean age of the participants was $29 \pm 5.8$ years (range: 22 to 55 years). Females represented $54 \%$ while males represented $46 \%$ of the sample. Most of the respondents were residents of Egypt with a percentage of $87.4 \%(n=437)$. The remaining proportion of the participants were residents of other Arab countries as KSA, UAE, Palestine, and Kuwait.

As for the professional practice, $39 \%$ of the respondents were working in public hospital clinics, $26.4 \%$ in private practices, $31.8 \%$ were staff members in public or private universities, 1.6 $\%$ of the participants were still in their internship period at the time of conducting the survey while only $1.2 \%$ were non-practicing dentists [Fig.1].

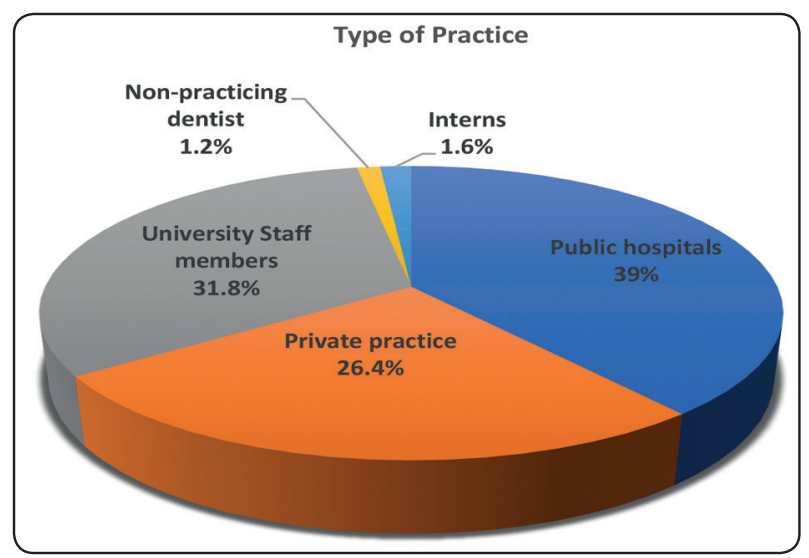

Fig. (1) Type of Practice of the Participants

Regarding the specialization of the respondents, general practitioners constituted $37.8 \%$ of the sample, $15.9 \%$ were pedodontists, $39.3 \%$ were of other specialities, while the rest of the respondents were still enrolled in internship or postgraduate programs at the time of taking the survey [Fig.2].

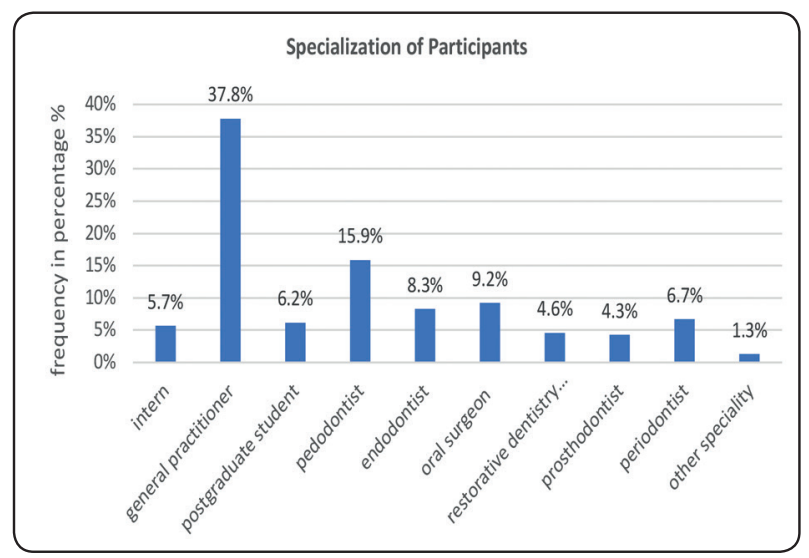

Fig. (2) Specialization of the Participants

\section{Knowledge Assessment}

Upon assessing the knowledge of the participating dentists regarding the action of antibiotics and the problem of bacterial resistance related to the antibiotics abuse, $92.6 \%$ of the answers revealed that antibiotics could be used to overcome infections of bacterial origin only while the rest of the participants assumed that antibiotics could also be used against infections of other origins as viral and parasitic. 
67.2\% believed that most dental infections are mixed in nature (caused by Aerobic and Anaerobic bacteria), while the rest of responses came in favour of either aerobic or anaerobic bacteria only.

97.2\% acknowledged the term antimicrobial resistance while only $2.8 \%$ of the participants were not aware of the problem. At the same time, $95.8 \%$ of the answers supported the concept that frequent and non-justified antibiotic prescriptions contribute to the bacterial resistance dilemma while the remaining proportion didn't recognize the causeeffect relationship. Also, 97\% of the participants believe that antibiotic resistance is an existing public health problem [Fig.3].

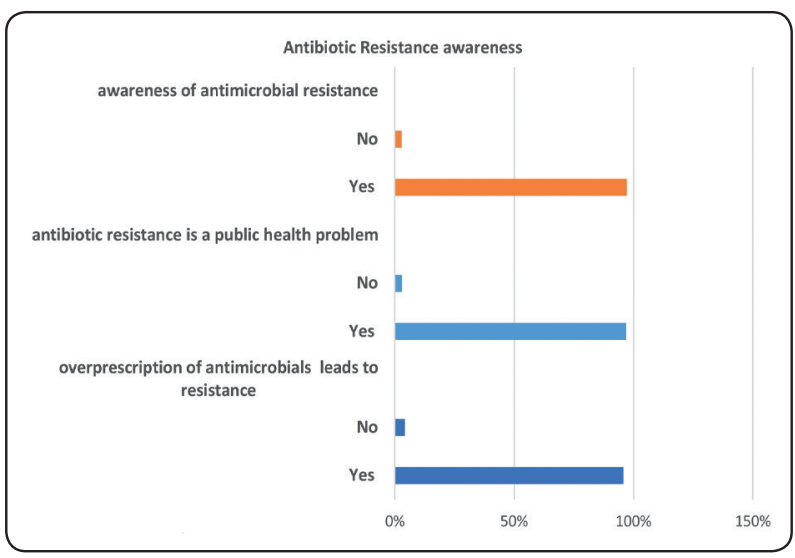

Fig. (3) Participants knowledge on Antimicrobial Resistance

\section{Attitude and Practice Assessment:}

$85.6 \%$ of the respondents reported that the problem of antibiotic resistance could pose a risk on the health of the entire community members, and $94 \%$ affirmed the need for more focused and in-depth teaching courses for undergraduates to help dentists make the proper decision regarding antibiotic prescriptions. Moreover, large scale campaigns raising the awareness of bacterial resistance and antibiotic abuse were recommended according to the responses of $91.8 \%$ of the sample.

The first choice of antibiotics categories prescribed by the participants was amoxicillin $52 \%$, amoxicillin + clavulanic acid combinations
$25.6 \%$. The rest of the responses came in favour of clindamycin and cephalosporins [Fig. 4].

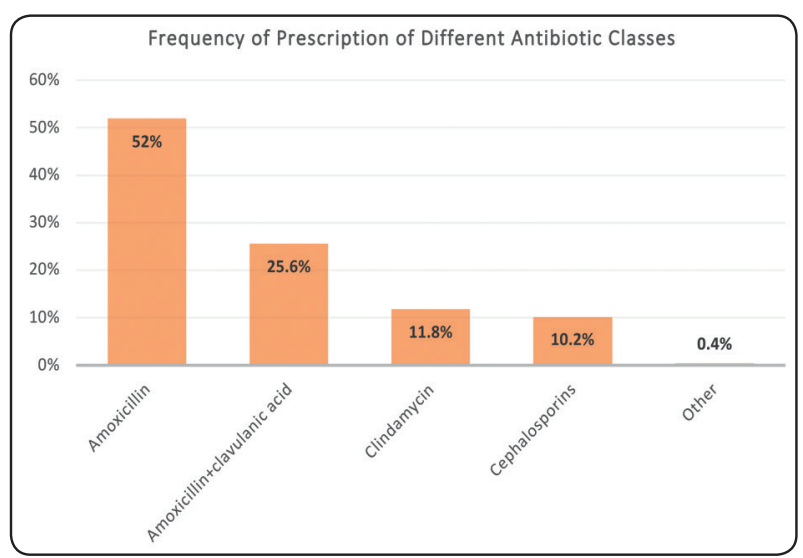

Fig. (4) Commonly Prescribed Antibiotics

The duration of antibiotic prescription ranged between 3 days up till the complete disappearance of signs and symptoms, where a 3-day duration regimen was adopted by $6 \%$ of the sample, $58.6 \%$ favoured a 5-day duration regimen, $28.6 \%$ opted for a seven-day duration and only $3.8 \%$ chose that their prescriptions should be extended for 10 days.

Also, $2.8 \%$ choices revealed that some participants preferred a duration more than 10 days while $0.4 \%$ of the participants recommended durations that might extend till complete disappearance of signs and symptoms without defining the number of days for the antibiotic course [Fig.5].

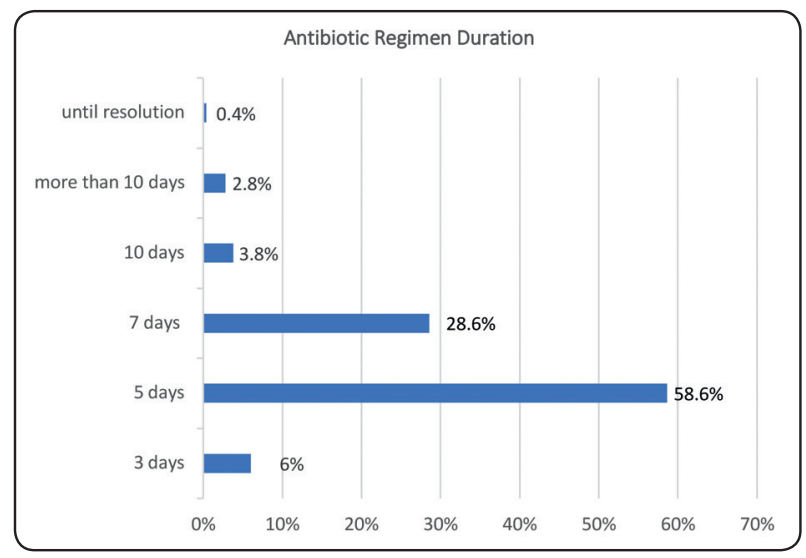

Fig. (5) Antibiotic Prescription Duration 
According to the adopted practices of the respondents while managing children and adolescents with various oral conditions, $96 \%$ would prescribe antibiotics in case of facial cellulitis, $29.6 \%$ of the participants responded that they would prescribe antibiotics in cases of Intra-oral localized dental swelling, while $19.4 \%$ responded to cases where sinus tract/ fistula was involved. In case of injuries to the dento/oral structures. $31.6 \%$ prescribed antibiotics in case of soft tissue lacerations, while $10.9 \%$ prescribed antibiotics in luxation injuries and avulsions. Only, $7.6 \%$ of the respondents would rather prescribe antibiotics for the management of viral infections causing oral ulcerations as Acute Herpetic gingivostomatitis [Fig.6].

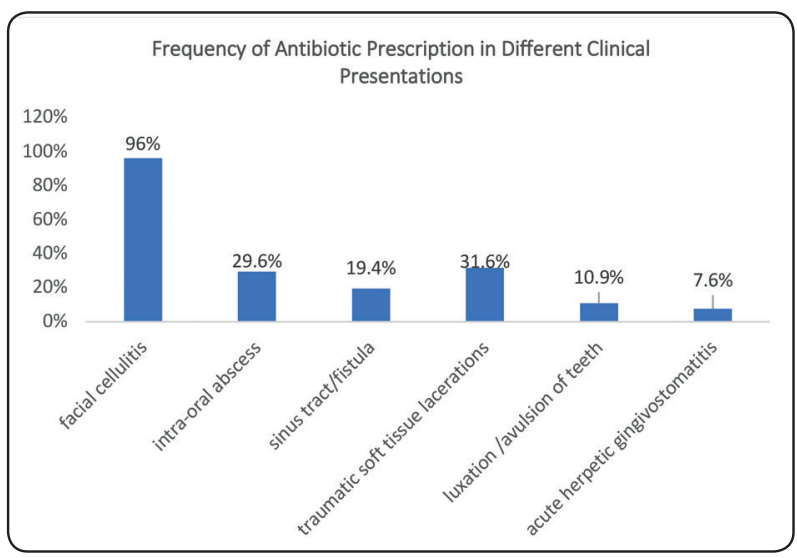

Fig. (6) Frequency of antibiotic prescriptions in different clinical situations

Regarding the proper management of cellulitis, $42.2 \%$ thought that antibiotic prescription should be combined with surgical drainage to achieve adequate resolution of the condition, while $54.1 \%$ thought that the antibiotics alone could suffice, only $3.7 \%$ chose surgical means without antibiotic prescription [Fig. 7].

In the event of emergent conditions, $70.2 \%$ of the respondents preferred the parenteral route of antibiotic administration over the oral route $27.8 \%$, while $2 \%$ of the inputs showed that the participants would rather prescribe antibiotics either through parenteral or oral routes [Fig. 8].

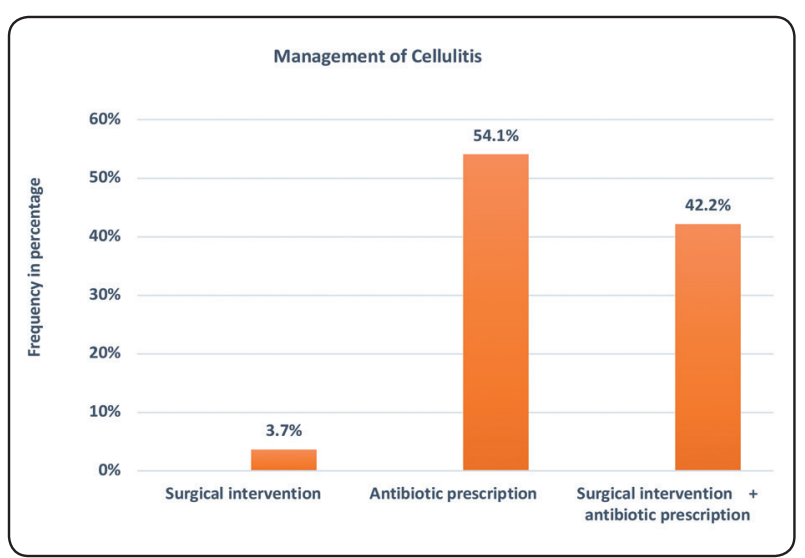

Fig. (7) Management of Facial Cellulitis

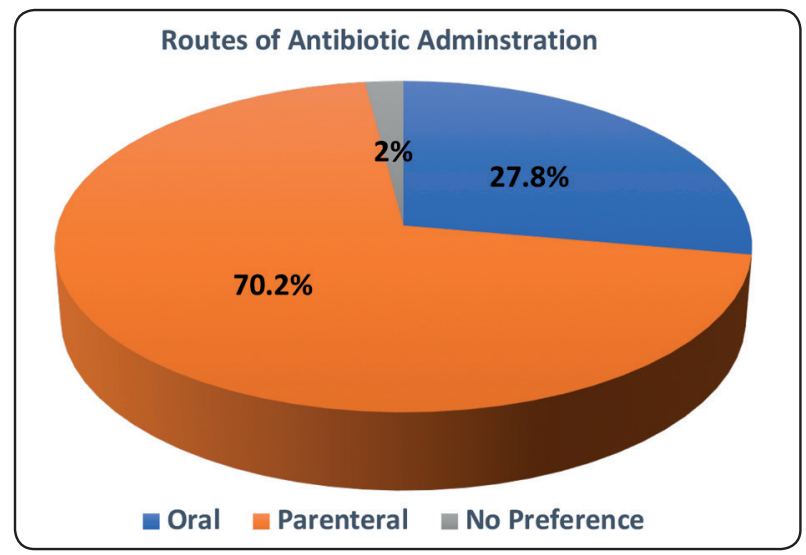

Fig. (8) Route of Antibiotic Administration

\section{DISCUSSION}

Given the potential contribution of dentistrybased antibiotic misuse to the problem of antimicrobial resistance and the paucity of literature on over-prescription of antibiotics in the pediatric population, these reasons provided the motivation to conduct this survey which is considered the first effort to describe knowledge, attitude and practice related to antibiotics prescriptions for children among a group of dentists who attended dental schools in Egypt. This objective, however, is similar to those of earlier surveys conducted in India ${ }^{[20]}$, USA $^{[21]}$, Canada ${ }^{[22]}$, and France ${ }^{[23]}$ using also online questionnaire forms.

The response rate of this survey, using Google Response form was $50 \%$, this is considered more than 
what is expected from on-line surveys that are not associated with follow-up e-mails or reinforcements which is the case in this research ${ }^{[24]}$. This was also comparable to the rate of a study conducted in Iran by Navabizadeh et al. ${ }^{[25]}$, in which a questionnaire was used to assess antibiotic prescriptions for endodontic infections and reported a response rate of $46.5 \%$. However, a higher response rate of $70 \%$ was obtained in a former study conducted in Lebanon by Mansour et al. ${ }^{[26]}$ which reported a response rate of $70 \%$. The later survey, however, was conducted via telephone interview of the participants which justifies higher response rate compared to e-mailed surveys which could be ignored or otherwise not completed by the recipients.

In order to assess whether the curricula utilized in the Egyptian universities in addition to further post graduate courses have provided the participants with adequate knowledge and awareness about antibiotics judicious usage, only graduates of Egyptian universities were considered in our sample, undergraduates were excluded since their knowledge is supposedly still incomplete till they graduate.

It was decided that the study sample to be diverse regarding the nature of practice of the participants as well as the type of specialization to help reflect on the all the information acquired in the dental school in addition to any latter experience in the academic or work environments. This diversity in the study sample was also advocated in former studies by Vasudavan et al. ${ }^{[21]}$, Baudet et al. ${ }^{[23]}$, and DenizSungur et al. ${ }^{[27]}$. Other studies, however, did not employ this diversity as the polish study conducted in $2015^{[28]}$, which investigated the knowledge of final year dental students on antibiotics use and the associated resistance problem.

Prudent antibiotic use requires adequate knowledge paralleled by proper practice and a favorable attitude towards their prescription. The results of this study show that most of the participants demonstrated adequate knowledge concerning, the target organisms on which the antibiotics act upon. They also acknowledge the term antimicrobial resistance and can recognize antimicrobial resistance as a current public health problem with the improper practice of over-prescription from the part of health professionals as a contributing factor. These results correspond to which obtained by Struzycka et al. ${ }^{[28]}$, where the authors also stated that (99\%) of the participants were aware that improper use of antibiotics could promote antimicrobial resistance, in addition (93\%) of their surveyed subjects considered antimicrobial resistance to be a significant problem.

In Egypt, a comparable survey carried on primary care providers with varying degrees of experience and work settings, also revealed that the respondents displayed a remarkable level of knowledge regarding identifying organisms targeted by the antibiotics, the acquaintance with the resistance problem and they can also relate some causal factors to the problem of resistance ${ }^{[29]}$.

On the other hand, a former study in UK, showed that almost all participants of the survey did not recognize that antibiotic resistance could be caused by the prescription behaviors of the health care professionals at that time, but could rather pose a risk in the future according to their account ${ }^{[30]}$.

It is also interesting to find that most of our participants agreed that the undergraduate teaching courses should focus more on proper antibiotic usage and that more awareness towards the problem should be raised through large scale campaigns. As opposed to this high proportion, only (43.7\%) of the dentists participating Baudet et al. survey ${ }^{[21]}$, testified that they were inadequately informed and trained regarding antibiotic use. However, (93\%) of them were rather interested in having updates of national recommendations in the form of practical sheets. Moreover, the same study highlighted that dentist are asking for a range of antibiotic stewardship strategies and wished to have prescription software considering the professional guidelines to help them make their clinical decisions more consistent. The need for clarifying the adopted guidelines had been 
suggested as claims concerning their vagueness were stated in a former study by Malik et al. ${ }^{[31]}$.

As regards to the practices of antibiotic use in clinical situations, the participants in the present study chose to prescribe antibiotics from the penicillin family namely amoxicillin, followed by penicillin combinations (amoxicillin + clavulanic acid), this finding was similar to that obtained by a previous survey research in $2018^{[31]}$, where researchers reported that amoxicillin was the drug of choice followed by metronidazole either alone or combined with amoxicillin in case of anaerobic infections, they stated that this practice was found to be more common among pediatric dentists in comparison to interns which reflected lack of knowledge among the interns compared to specialists regarding the nature of odontogenic infections which affected their clinical decisions. Likewise, Amoxicillin was also considered the drug of choice according to previous surveys in many countries conducted regionally and offshore as in Kuwait ${ }^{[5]}, \mathrm{KSA}^{[32]}$, UAE ${ }^{[33]}$, UK ${ }^{[34]}$ and Spain ${ }^{[35]}$.

We could assume that the participants' awareness of the resistance problem, made them recognize that antibiotic combinations broaden the spectrum of action of the medication which could affect pathogenic as well as commensal bacteria, that is why they chose amoxicillin more. Another valid point to be considered here, is that more than $70 \%$ of our respondents are dealing with low-income patients that are usually encountered through their practice in the university or public hospitals, and that patients' financial status might have influenced the decisions towards choosing cheaper medications.

In contradiction, a survey in KSA by Iqbal [36] reported that amoxicillin and clavulanic acid in combination was considered the most adopted regimen for managing odontogenic infections followed by amoxicillin only and amoxicillin combined with metronidazole was the least utilized alternative. The authors further justified that the surveyed dentists basically preferred the combination of (amoxicillin and clavulanic acid) as it was reported earlier to have lower incidence of bacterial resistance compared to amoxicillin alone ${ }^{[37]}$.

Even though the doses are well established by pharmacokinetic studies, the duration of antibiotic therapyisstillnotclear,though shorttreatmentcourses are preferred to more protracted courses especially when dealing with children, as the practitioners usually encounter the problem of compliance, for this reason higher doses of antibiotics given for a shorter duration is encouraged ${ }^{[4,38]}$. Treatment of most odontogenic infections requires an average of 5 to 7 days of therapy; however, treatment of severe infections or immunocompromised patients' therapy can be of longer duration owing to reduced immunity ${ }^{[39]}$.

In line with that, (93.2\%) of the dentists in this study adopted antibiotic duration regimens up to 7 days, and (64.6\%) preferred (3-5 days) courses. The results obtained earlier in 2018 by Malik et al. ${ }^{[31]}$ showed even more tendencies towards shorter durations that most of the dental specialists and interns included in their survey adopted (a 3-day regimen) in their prescriptions.

On the other hand, Inchara et al. ${ }^{[20]}$, reported that only $(34 \%)$ of their respondents prescribed antibiotics on average of 2-6 days, while the rest of their sample favored durations of 7 days or more. Furthermore, earlier surveys in USA ${ }^{[39]}$ and Canada ${ }^{[22]}$ showed that dentists tend to prescribe antibiotics with average durations of 7.6 days and 7 days respectively. It is worth mentioning here that, the latter two surveys did not involve pediatric dentists and hence the problem of compliance was not a major concern in any.

It should be noted however, that there is a false conception that antibiotics should be used for a certain number of days, the most updated recommendation though is following patient's symptoms daily and ceasing antibiotics when the symptoms are resolved ${ }^{[40]}$. 
The clinical situations that require antibiotic therapy are limited, and they include oral infections accompanied by elevated body temperature and evidence of systemic spread, such as lymphadenopathy and trismus. Among which is "Facial Cellulitis", which is a serious condition that should be treated promptly by antibiotics because of the possibility of spread of infection via lymph and blood circulation, with potential development of septicaemia ${ }^{[41]}$.

It is evident that our respondents showed considerable awareness regarding the seriousness of this condition, as $96 \%$ of the dentists chose that they would prescribe antibiotics for patients with facial cellulitis, which reflects a notable adherence to the guidelines regarding this condition and this goes in accordance with the results of a survey conducted earlier in USA by Vasudavan et al. ${ }^{[21]}$ who reported that $99 \%$ of their respondents would prescribe antibiotics for cellulitis regardless the years of practice. Also, Deniz-Sungur et al. [27], reported similar findings in their research that was published in 2020 .

On the other hand, only $31.6 \%$ of the respondents supported antibiotic prescriptions in cases of oral lacerations/ wounds, despite it is advised that intraoral lacerations that appear to have been contaminated by extrinsic bacteria, debris (e.g., dirt, soil, gravel), foreign body, open fractures, and joint injury have an increased risk of infection and should be managed by systemic antibiotics ${ }^{[42]}$.

Moreover, a considerable proportion of the responses showed that dentists in the current survey would utilize antibiotics for the management of conditions that do not warrant their use as in localized dentoalveolar abscess or chronic forms of infection as the presence of sinus tracts or fistulas, or even oral ulcerations of viral origin, and so violation of the guidelines set forth by AAPD ${ }^{[43]}$ is clearly evident.

In addition, a quite minor "yet not to be ignored" percentage $(10.9 \%)$ of the dental practitioners responding to this survey would use antibiotics in cases of luxation injuries and replantation of avulsed teeth, despite that systemic use of antibiotics for such conditions has been questioned and the clinical studies do not support such practice ${ }^{[44]}$.

Alkhabuli et al. ${ }^{[33]}$ also stated that, the management of localized swellings was uncertain among their respondents whether being general practitioners or specialists, half of their sample tended to prescribe antibiotics, while local interventions were just adequate. Similar surveys conducted in Jordan ${ }^{[45]}$, and Saudi Arabia ${ }^{[32]}$ also reported a definite over-prescription of drugs by practising dentists in similar clinical situations that could be successfully managed by local measures.

These forms of discrepancies between the decisions of the clinicians and the adopted guidelines, were even described by Sivaraman et al. [46] amongst the members of AAPD with a tendency to overprescribe and overuse antibiotics in certain conditions like irreversible pulpitis and localized abscesses with or without sinus tract and draining fistula.

The same guidelines also encourage using antibiotics as adjuncts in certain prophylactic and therapeutic conditions after adequate assessment of systemic spread of infection and the risk factors of the patient. However, it is rather discouraging to know that almost half of the participants in the current survey consider antibiotic prescription alone could help alleviate the acute symptoms (as in facial cellulitis) adequately, though surgical drainage is doomed necessary in emergency treatments both for the relief of the patient by the removal of toxic products and for the antibiotic to disseminate into the infected space more readily ${ }^{[4]}$. Zakri et al. ${ }^{[4]]}$, also reported that almost one third of their sample invalidly believed that systemic antibiotics alone could be useful for managing acute facial swellings in emergency visits.

As the current study reports even a higher percentage than that of the previous survey, this could be partly attributed to the fact that more than $70 \%$ of the sample work in public and university hospitals and their clinical decisions could have been affected 
by the demanding workflow or the long waiting lists of patients, that sometimes a prescription could be given to the patient and the surgical drainage would be incorrectly deferred to a later visit.

It has been stated that a more safe and convenient way of medication administration is achieved via oral route compared to parenteral routes ${ }^{[48]}$. Despite of that, a little less than three quarters of the respondents preferred the parenteral route of administration over the oral route, this finding however was not backed up with sufficient evidence that IM/IV routes were more efficient in managing life threatening conditions as facial cellulitis. This finding coincides with the results of Inchara, et al. [20] who reported that only $29 \%$ of their participants preferred the oral route of administration over the parenteral routes. On the contrary, $99 \%$ of the responses of the survey conducted earlier in Turkey ${ }^{[27]}$ came in favor of the oral route compared to the more invasive routes. This inconsistency between our results and those of the later study could be resorted to variation of the target patients to which the antibiotic is prescribed, where in our study we were concerned about prescriptions given to pediatric patients, and this was the case also with the Indian study ${ }^{[20]}$ however, the Turkish study was rather concerned with endodontic clinical situations in adult patients.

We can argue that may be our participants think it is more practical to use parenteral routes especially if the patient is suffering from an acute condition as facial cellulitis rather than struggling with the patients' compliance to oral medications that might not be palatable to young patients and instead the medication will be misused by skipping doses or by underusage. Moreover, the guidelines are not clear on this concern which could make some clinical decisions on the route of administration uncertain, and that clinicians rather opt for parenteral routes to ensure sufficient plasma levels of the medications in a short time in order to halt the spread of infections.

Given the observations elucidated in the results, this study could provide preliminary data regarding extent to which professionals' practices go in accordance with the professional guidelines and it could serve as a basis for further research and scrutiny.

Nevertheless, there are still some limitations in the current study that need to be clarified, as the dentists who chose to respond to the survey may not have been a true representation of all dentists who had their dental education in Egyptian universities. Moreover, this study is cross-sectional in nature which makes it impossible to conclude causal inferences. Also, given that the survey was completed voluntarily, the inputs could be subject to response bias; moreover, we cannot also exclude a selection bias, as the respondents might be more aware of antibiotic related practices and drug resistance problems compared to others not participating in this study, and in such condition, malpractices depicted here could be underestimated.

\section{CONCLUSIONS}

Although the participants showed considerably adequate knowledge of the bacterial resistance problem, their practices however, showed varying degrees of deviation from the guidelines of antibiotic prescriptions set by the AAPD, depicted mainly as over-prescriptions in conditions that do not require antibiotic usage. And these mal practices could contribute directly to the problem of antimicrobial resistance.

\section{RECOMMENDATIONS}

In the view of the current results and drawn conclusions it is recommended that:

- Academic curricula in dental schools should put more emphasis on antibiotics and their possible risks especially those related to antibiotic misuse in dental practice.

- National health authorities could help improve dentists' practices and clinical decisions through providing them with adequate tools and enrolling them in programs which boost their knowledge and understanding of the guidelines concerned with antibiotic prescriptions. 


\section{REFERENCES}

1. Agarwal S, Yewale VN, Dharmapalan D. (2015) Antibiotics Use and Misuse in Children A Knowledge, Attitude and Practice Survey of Parents in India. J Clin Diagn Res 9(11):SC21-SC24. https://doi.org/10.7860/ JCDR/2015/14933.6819

2. Ramasamy A (2014) A review of use of antibiotics in dentistry and recommendations for rational antibiotic usage by dentists. The International Arabic Journal of Antimicrobial Agents 4(2) https://doi.org/10.3823/748.

3. Goud SR, Nagesh L, Fernandes S (2012) Are we eliminating cures with antibiotic abuse? A study among dentists. Niger J Clin Pract.;15(2):151-155. https://doi. org/10.4103/1119-3077.97291

4. Dar-Odeh NS, Abu-Hammad OA, Al-Omiri MK, Khraisat AS, Shehabi AA (2010) Antibiotic prescribing practices by dentists: a review. Ther Clin Risk Manag 6:301-306. https://doi.org/10.2147/tcrm.s9736

5. Salako NO, Rotimi VO, Adib SM, Al-Mutawa S (2004) Pattern of antibiotic prescription in the management of oral diseases among dentists in Kuwait. J Dent 32(7):503-509. https://doi.org/10.1016/j.jdent.2004.04.001

6. Pallasch TJ (2003) Antibiotic resistance. Dent Clin North Am 47(4):623-639. https://doi.org/10.1016/s00118532(03)00039-9

7. WHO's first global report on antibiotic resistance reveals serious, worldwide threat to public health. [Internet]. 2014. Available from: http://www.who.int/mediacentre/news/releases/2014/amr-report/en/

8. Centers for Disease Control and Prevention. Antibiotic/ Antimicrobial Resistance Threats in the United States, 2013. Available at: "https://www.cdc.gov/drugresistance/ threat-report-2013/pdf/ar-threats-2013-508.pdf

9. Kumarasamy KK, Toleman MA, Walsh TR, et al (2010) Emergence of a new antibiotic resistance mechanism in India, Pakistan, and the UK: a molecular, biological, and epidemiological study. Lancet Infect Dis 10(9):597-602 https://doi.org/10.1016/S1473-3099(10)70143-2

10. Franco BE, Altagracia Martinez M, Sanchez Rodriguez MA WA (2009) The determinants of the antibiotic resistance process. Infect Drug Resist 2:1-11. https://www. ncbi.nlm.nih.gov/pubmed/21694883

11. Sharma D, Patel RP, Zaidi STR, Sarker MMR, Lean QY ML (2017) Interplay of the Quality of Ciprofloxacin and
Antibiotic Resistance in Developing Countries. Frontiers in pharmacology. Front Pharmacol 8:546. https://doi. org/10.3389/fphar.2017.00546

12. Shaikh BT. Anti-Microbial Resistance In Pakistan (2017) A Public Health Issue. Journal of Ayub Medical College, Abbottabad : JAMC29: 184-185. PMID: 28718227

13. Centers for Disease Control and Prevention. Methicillin Resistant Staphylococcus aureus Methicillin Resistant Staphylococcus aureus. "www.cdc.gov/mrsa/" Accessed 25th august 2018. 2011;1-23.

14. Kouyos RD, Metcalf CJ, Birger R, et al (2014) The path of least resistance: aggressive or moderate treatment?. Proc Biol Sci 281(1794):20140566.https://doi.org/10.1098/ rspb.2014.0566

15. CherryWR, Lee JY, Shugars DA, White, R PJr, \& Vann WF $\mathrm{Jr}$ (2012). Antibiotic use for treating dental infections in children: a survey of dentists' prescribing practices. Journal of the American Dental Association (1939), 143(1), 31-38. https://doi.org/10.14219/jada.archive.2012.0015

16. El-Hawy RM, Ashmawy MI, Kamal MM, et al (2017) Studying the knowledge, attitude and practice of antibiotic misuse among Alexandria population. Eur J Hosp Pharm 24(6):349-354. https://doi.org/10.1136/ejhpharm-2016-001032

17. Konde S, Jairam LS, Peethambar P, Noojady SR, \& Kumar NC. (2016). Antibiotic overusage and resistance: A cross-sectional survey among pediatric dentists. Journal of the Indian Society of Pedodontics and Preventive Dentistry, 34(2), 145-151. https://doi.org/10.4103/09704388.180444

18. Smith CR, Pogany L, Foley S, Wu J, Timmerman K, GaleRowe M, Demers A (2017) Canadian physicians' knowledge and counseling practices related to antibiotic use and antimicrobial resistance: Two-cycle national survey. Can Fam Physician.;63(12):e526-e535.

19. Kaul R, Angrish P, Jain P, Saha S, V Sengupta A, \& Mukherjee S (2018) A Survey on the Use of Antibiotics among the Dentists of Kolkata, West Bengal, India. International journal of clinical pediatric dentistry, 11(2), 122-127. https://doi.org/10.5005/jp-journals-10005-1497

20. Inchara R, Ganapathy D, Kumar PK (2019) Preference of antibiotics in pediatric dentistry. Drug Invent Today 11:1495-98. [Google Scholar] 
21. Vasudavan S, Grunes B, Mcgeachie J, Sonis AL (2019) Antibiotic Prescribing Patterns Among Dental Professionals In Massachusetts. Pediatr Dent. Jan 15;41(1):25-30. PMID: 30803473.

22. Epstein JB, Chong S, Le ND (2000) A survey of antibiotic use in dentistry. J Am Dent Assoc 131:1600-9. https://doi. org/10.14219/jada.archive.2000.0090.

23. Baudet A, Kichenbrand C, Pulcini C, Descroix V, Lesclous P, Thilly N, Clément C, \& Guillet J (2020) Antibiotic use and resistance: a nationwide questionnaire survey among French dentists. European journal of clinical microbiology $\&$ infectious diseases : official publication of the European Society of Clinical Microbiology 39(7), 1295-1303. https://doi.org/10.1007/s10096-020-03849-0

24. Fincham JE (2008) Response rates and responsiveness for surveys, standards, and the Journal. Am J Pharm Educ 72(2):43-43. https://doi.org/10.5688/aj720243 PMID: 18483608

25. Nabavizadeh MR, Sahebi S, Nadian I (2011) Antibiotic prescription for endodontic treatment: general dentist knowledge + practice in shiraz. Iran Endod $\mathrm{J}$ Spring;6(2):54-9. Epub 2011 May 15. PMID: 23130054; PMCID: PMC3487514.

26. Mansour H, Feghali M, Saleh N, Zeitouny M (2018) Knowledge, practice and attitudes regarding antibiotics use among Lebanese dentists. Pharm Pract (Granada) Jul-Sep;16(3):1272. doi: 10.18549/PharmPract.2018.03.1272. Epub 2018 Sep 29. PMID: 30416630; PMCID: PMC6207361.

27. Deniz-Sungur D, Aksel H, Karaismailoglu E, \& Sayin TC (2020) The prescribing of antibiotics for endodontic infections by dentists in Turkey: a comprehensive survey. International endodontic journal, 53(12), 1715-1727. https:// doi.org/10.1111/iej.13390

28. Struzycka I, Mazinska B, Bachanek T, Boltacz-Rzepkowska E, Drozdzik A, Kaczmarek U, Kochanska B, Mielczarek A, Pytko-Polonczyk J, Surdacka A, Tanasiewicz M, Waszkiel D, Hryniewicz W (2019) Knowledge of antibiotics and antimicrobial resistance amongst final year dental students of Polish medical schools-A cross-sectional study. Eur J Dent EducAug;23(3):295-303. https://doi. org/10.1111/eje.12430

29. El-Sokkary R, Kishk R, Mohy El-Din S, Nemr N, Mahrous N, Alfishawy M, Morsi S, Abdalla W, Ahmed M, Tash R (2021) Antibiotic Use and Resistance Among Prescribers: Current Status of Knowledge, Attitude, and Practice in Egypt. Infect Drug Resist.;14:1209-1218. https://doi. org/10.2147/IDR.S299453

30. Dyar OJ, Hills H, Seitz LT, Perry A, Ashiru-Oredope D (2018) Assessing the knowledge, attitudes and behaviors of human and animal health students towards anti- biotic use and resistance: a pilot cross-sectional study in the UK. Antibiotics Basel7:E10. https://doi.org/10.3390/antibiotics7010010

31. Malik A, Sharma K, Sachdev V, Mathur S (2018) Knowledge and Attitude of dentists towards antibiotic use in children: A cross-sectional survey. J Dent Spec 6(1):56-59. https://doi.org/10.18231/2393-9834.2018.0013

32. Al-Johani K, Reddy SG, Al Mushayt AS, El-Housseiny A (2017) Pattern of prescription of antibiotics among dental practitioners in Jeddah, KSA: A cross-sectional survey. Niger J Clin Pract. 20(7):804-810. https://doi. org/10.4103/1119-3077.196072

33. Alkhabuli J, Kowash M, Shah A (2016) Knowledge and Attitude of Northern Emirates Dental Practitioners towards Antibiotic Prescription and its Resistance. Int J Dent Oral Health 2:177. https://doi.org/10.16966/2378-7090.177

34. Tulip DE, Palmer NO (2008) A retrospective investigation of the clinical management of patients attending an out of hours dental clinic in Merseyside under the new NHS dental contract. Br Dent J. 205(12):659-648. https://doi. org/10.1038/sj.bdj.2008.1044

35. Segura-Egea JJ, Velasco-Ortega E, Torres-Lagares D, Velasco-Ponferrada MC, Monsalve-Guil L, Llamas-Carreras JM (2010) Pattern of antibiotic prescription in the management of endodontic infections amongst Spanish oral surgeons. Int Endod J. 43(4):342-350. https://doi. org/10.1111/j.1365-2591.2010.01691.x

36. Iqbal A (2015) The Attitudes of Dentists Towards the Prescription of Antibiotics During Endodontic Treatment in North of Saudi Arabia. J Clin Diagn Res. 9(5):ZC82ZC84. https://doi.org/10.7860/JCDR/2015/13718.5964

37. Keenan JV, Farman AG, Fedorowicz Z, Newton JT (2005) Antibiotic use for irreversible pulpitis. Cochrane Database Syst RevApr 18;(2):CD004969. https://doi. org/10.1002/14651858.CD004969.pub2. Update in: Cochrane Database Syst Rev. 2013;12:CD004969. PMID: 15846738 .

38. Rubinstein E (2007) Short antibiotic treatment courses or how short is short? Int J Antimicrob Agents 30(Suppl 1):S76-9. https://doi.org/10.1016/j.ijantimicag.2007.06.017 
39. Yingling NM, Byrne BE, Hartwell GR (2002) Antibiotic use by members of the American association of endodontists in the year 2000: Report of a national survey. J Endod 28:396404. https://doi.org/10.1097/00004770-200205000-00012

40. Segura-Egea JJ, Martin-Gonzalez J, Jimenez-Sanchez MDC, Crespo-Gallardo I, Sauco-Marquez JJ, VelascoOrtega E (2017b) Worldwide pattern of antibiotic prescription in endodontic infections. International Dental Journal 67, 197- 205 .

41. Oberoi, S.S., Dhingra, C., Sharma, G. and Sardana, D (2015) Antibiotics in dental practice: how justified are we. Int Dent J, 65: 4-10. https://doi.org/10.1111/idj.12146.

42. Goel D, Goel GK, Chaudhary S, Jain D (2020) Antibiotic prescriptions in pediatric dentistry: A review. J Family Med Prim Care. 9(2):473-480. Published 2020 Feb 28. https://dx.doi.org/10.4103\%2Fjfmpc.jfmpc_1097_19

43. American Academy of Pediatric Dentistry (2020) Use of antibiotic therapy for pediatric dental patients. The Reference Manual of Pediatric Dentistry. Chicago, Ill.: American Academy of Pediatric Dentistry; 443-6.

44. Levin L, Day PF, Hicks L, O'Connell A, Fouad AF, Bour- guignon C, Abbott PV. International Association of Dental Traumatology guidelines for the management of traumatic dental injuries: General introduction. Dent Traumatol. 2020 Aug;36(4):309-313. doi: 10.1111/edt.12574. Epub 2020 Jun 22. PMID: 32472740.

45. Abu-zineh R, Dar-Odeh N, Shehabi A (2015) Macrolide resistance genes and virulence factors of common viridans Streptococci species colonizing oral cavities of patients in Jordan. Oral Health Dent Manag14:337-41. http://dx.doi. org/10.4172/2247-2452.1000839

46. Sivaraman SS, Hassan M, Pearson JM (2013) A national survey of pediatric dentists on antibiotic use in children. Pediatr Dent 35(7): 546-549. PMID: 2455328.

47. Zakri N, Alshehri1 N, Shebli A (2018) Antibiotic Practicing Habits, Knowledge and Attitude toward Education about Antibiotics among Dentists in Jazan City. The Egyptian Journal of Hospital Medicine, 72(3), 4207-4217. doi: 10.21608/ejhm.2018.9140

48. Lee SL, Azmi S, Wong PS. Clinicians' knowledge, beliefs and acceptance of intravenous-to-oral antibiotic switching, Hospital Pulau Pinang (2012) Med J Malaysia. 67:1908. [PubMed] [Google Scholar] PMID: 22822642 